\title{
Author reply
}

\author{
Chang Hak Yoo
}

Published online: 18 August 2009

(C) Springer Science+Business Media, LLC 2009

We thank Dr. Kanellos and colleagues for their supportive response to our article entitled Short-Term Outcomes of Laparoscopic-Assisted Distal Gastrectomy for Gastric Cancer During a Surgeon's Learning Curve Period [1]. The article aimed to show that laparoscopically assisted distal gastrectomy (LADG) performed by an experienced gastric surgeon who has no experience with laparoscopic surgery is a feasible alternative for treating early gastric cancer (EGC).

Certainly, as they have underscored, this procedure may entail a considerable learning curve for surgeons in the West, where the incidence of gastric cancer or EGC is lower than in the East. However, we want to emphasize that open distal gastrectomy (ODG) and LADG are not two different things. As shown in many studies, LADG can be performed with acceptable perioperative complication rates similar to those for ODG [1-3]. Thus we believe that adequate experience with ODG is an ignition key for starting the LADG car and that familiarization with laparoscopic skills is an accelerator for going over the "learning curve" hill.

We agree with Dr. Kanellos and colleagues that the impact of extended lymph node dissection on long-term survival still is under debate because randomized studies have shown no evidence of a statistically significant improvement in survival with D2 lymph node dissection. However, in Korea and Japan, D2 lymph node dissection has long been the standard treatment, even for EGC, with lower morbidity and mortality rates than in the West. Especially for submucosal cancer, the incidence of metastasis in the group 2 lymph nodes, such as those along the left

\section{H. Yoo $(\bowtie)$}

Department of Surgery, Kangbuk Samsung Hospital

Sungkyunkwan University School of Medicine, 108 Pyung-Dong, Jongno-Ku, Seoul, South Korea e-mail: ch63.yoo@samsung.com gastric artery, the common hepatic artery, the splenic artery, and the celiac trunk, is reportedly as high as $6 \%$. Furthermore, the accuracy of preoperative pT staging has been far from satisfactory until the time of this writing. Therefore, we think that at least $\mathrm{D} 1+\beta$ or $\mathrm{D} 2$ lymph node dissection is needed for LADG except in the case of a definite small mucosal cancer.

Finally, recent issues in laparoscopic gastric surgery are moving toward the feasibility and safety of performing laparoscopic surgery for advanced gastric cancer (AGC). Our recently published article [4] and the results shown by the Italian group suggest that laparoscopic gastrectomy is feasible for the treatment of both AGC and EGC. However, a definite conclusion regarding the application of laparoscopic surgery for AGC awaits the accumulation of data, preferably obtained through multicenter randomized controlled trials.

\section{References}

1. Yoo CH, Kim HO, Hwang SI, Son BH, Shin JH, Kim H (2009) Short-term outcomes of laparoscopic-assisted distal gastrectomy for early gastric cancer during a surgeon's learning curve period. Surg Endosc. Epub ahead of print

2. Park JM, Jin SH, Lee SR, Kim H, Jung IH, Cho YK, Han SU (2008) Complications with laparoscopically assisted gastrectomy: multivariate analysis of 399 consecutive cases. Surg Endosc 22:2133-2139

3. Kim W, Song KY, Lee HJ, Han SU, Hyung WJ, Cho GS (2008) The impact of comorbidity on surgical outcomes in laparoscopyassisted distal gastrectomy: a retrospective analysis of multicenter results. Ann Surg 248:793-799

4. Hwang SI, Kim HO, Yoo CH, Shin JH, Son BH (2008) Laparoscopic-assisted distal gastrectomy versus open distal gastrectomy for advanced gastric cancer. Surg Endosc 23:1252-1258 